\title{
Effect of Cholecystokinin-A Receptor Antagonist on Rat Pancreas after Partial Pancreatectomy
}

\author{
Kimiya Handa ${ }^{1}$, Tetsutaro Suzuki ${ }^{1}$, Keiko Hayashi ${ }^{1}$, Tsuyoshi Takahashi, \\ Akira Kakita $^{1}$ and Shohei Yamashina ${ }^{2}$ \\ Departments of ${ }^{1}$ Surgery and ${ }^{2}$ Anatomy, Kitasato University School of Medicine, 1-15-1, Kitasato, Sagamihara, Kanagawa \\ 228-8555, Japan
}

Received May 21, 2003; accepted October 21, 2003

Our previous study indicated that the acinar cells regenerated actively in the rat pancreatic remnant after partial $(90 \%)$ pancreatectomy. On that occasion, a twofold higher mitotic activity was observed in the cells of paraduodenal than those of the medial and stump regions (regional difference). Since cholecystokinin (CCK) has been known to have various physiological functions in the digestive system, especially in the pancreas, through the CCK-A receptor, we determined the effect of a CCK-A receptor competitive antagonist (CCK-RA) (SR27897B) on pancreatic regeneration after pancreatectomy. A group of Wistar rats was administered $1 \mathrm{mg} / \mathrm{kg}$ CCK-RA twice daily for 5 days. On the 2 nd day of administration, partial pancreatectomy was performed. Proliferation activity of both exocrine and endocrine cells was found to be enhanced uniformly 5 days after the pancreatectomy, and the effect was inhibited by CCK-RA. Plasma CCK level was increased by $90 \%$ pancreatectomy and decreased by CCK-RA. CCK was hypothesized to be an important factor of pancreatic exocrine and endocrine regeneration. Administration with CCK-RA suppressed mitotic activity uniformly in the three regions of paraduodenal, medial and stump. From the evidence, it was presumed that regional difference in regeneration was produced not by paracrine factor from the duodenum but by some other unknown mechanism including anatomical difference in vascular and autonomic nervous system.

Key words: pancreas, regeneration, pancreatectomy, cholecystokinin, cholecystokinin-A receptor antagonist

\section{Introduction}

Experimental pancreatic regeneration was first studied in dog by DiMattei [5] in 1885, who determined the mitotic activity of pancreatic cells after partial pancreatectomy. Extensive studies by Fitzgerald et al. [6] and Pearson et al. [22] demonstrated regeneration of pancreatic acinar cells after partial pancreatectomy. Besides partial pancreatectomy, subsequent studies indicated that the pancreatic tissue was able to regenerate after various experimental treatments such as ductal ligation and drug administration. Experimental regeneration has been applied to determine the controlling mechanism of cellular proliferation in the pancreas. Previ-

Correspondence to: Dr. Shohei Yamashina, Department of Anatomy, Kitasato University School of Medicine, 1-15-1, Kitasato, Sagamihara, Kanagawa 228-8555, Japan. E-mail: yamasina@kitasato-u.ac.jp ous studies by our group has demonstrated that after $90 \%$ pancreatectomy, the remnant pancreas regenerated immediately and reached the maximum at around day $5[9,10]$. Immunohistochemical study also indicated that there was a regional difference in proliferation activity in the remnant pancreas [9]. The proliferation activity was higher in the paraduodenal region than that in medial and stump regions. These findings suggest that acinar cells may be affected by some humoral factors possibly produced by the duodenum. Among various hormones and growth factors related to regeneration, cholecystokinin (CCK) has been suggested to be a potent humoral factor affecting trophism of the pancreas [1, 3, 11, 13, 20, 23-25, 27, 29, 30]. Miyasaka et al. [18] has reported that CCK is essential not only for normal pancreatic growth, but also for pancreatic regeneration after partial pancreatectomy. Therefore we hypothesized that CCK, which promotes various physiological processes, 


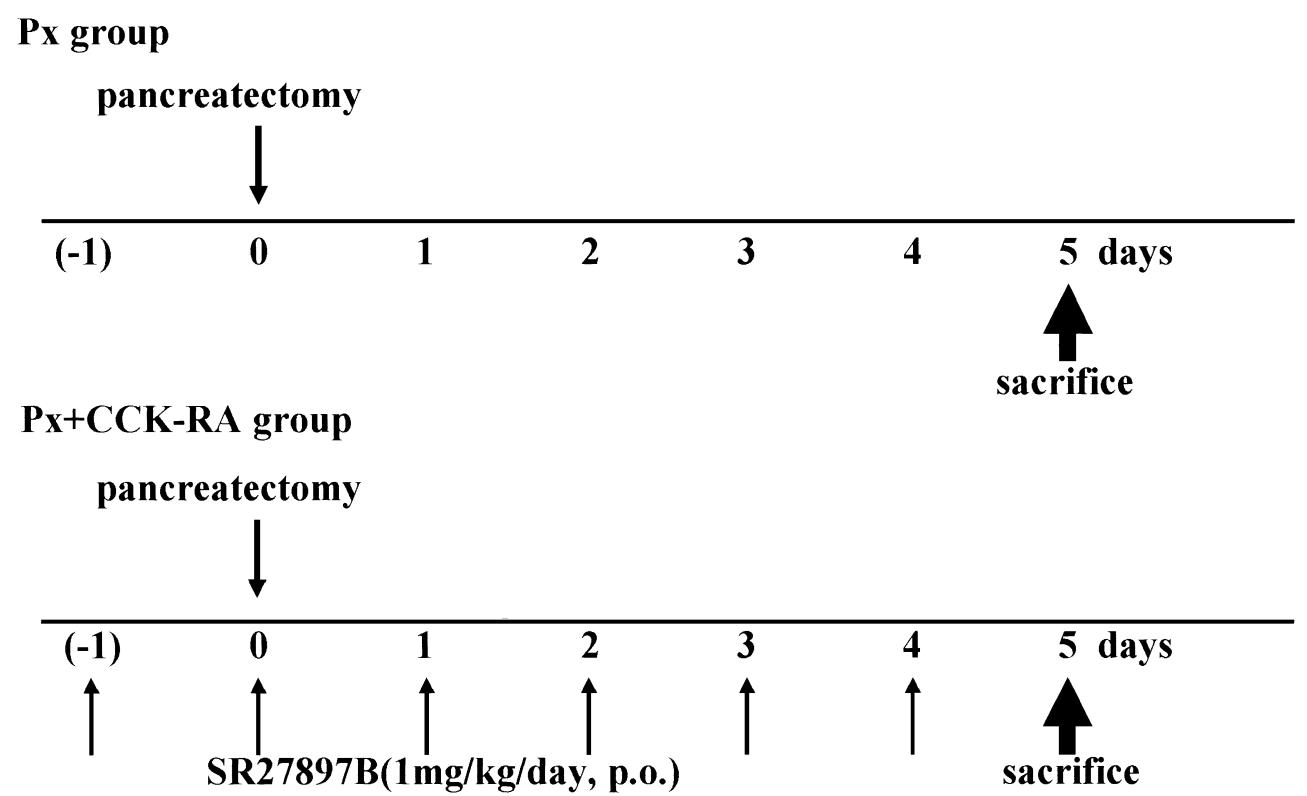

Fig. 1. Experimental protocol.

might play an important role in the course of regeneration. In this study we attempted to determine the effect of CCK on the process of pancreatic regeneration using a CCK receptor antagonist (CCK-RA), SR27897B, paying special attention to the regional difference.

\section{Materials and Methods}

\section{Experimental animals and pancreatectomy}

Male Wistar rats weighing 120-150 g (6 weeks of age) were housed in an air conditioned room at $23^{\circ} \mathrm{C}$ with a diurnal light and dark schedule, and were allowed free access to water and standard food before and after the operation. Partial pancreatectomy was performed according to Hayashi et al. $[9,10]$ under anesthesia with intraperitoneal injection ( $1 \mathrm{ml} / 100 \mathrm{~g}$ body weight $)$ of a mixture containing $35 \mathrm{mg}$ sodium pentobarbital (Dainihon Pharmaceutical Co., Ltd., Osaka, Japan) and $15 \mathrm{mg}$ ketamin hydrochloride (Sankyo Pharmaceutical Co., Ltd., Tokyo, Japan) in $1 \mathrm{ml}$ physiological saline. The gastric, splenic and duodenal segments of the pancreas were resected, leaving only the parabiliary segment, the smallest portion closely attached to the common bile duct [28]. Pancreatic resection was performed using a battery-operated small vessel cauterizer equipped with a straight tip (Fine Science Tools, Heidelberg, Germany). By this procedure, about $90 \%$ by wet weight of the total pancreas was resected. All surgical procedures in this study were started at 10 a.m. and were completed within approximately $20 \mathrm{~min}$.

\section{CCK-RA administration}

A group of rats was administered with SR27897B ( $1 \mathrm{mg} / \mathrm{kg}$ body weight) per os twice daily from 1 day before pancreatectomy to the indicated day of sacrifice (Fig. 1).
SR27897B is a non-peptide competitive antagonist of the CCK-A receptor $[4,8,14-16]$ and was kindly supplied by Japan Sanofi Co., Ltd. Another group of rats was treated only by pancreatectomy. The third group was sham-operated.

\section{Tissue sampling and microscopic examination}

On day 5 after pancreatectomy, the remnant pancreas was removed en bloc together with the surrounding duodenum and was prepared for microscopic examination. In a separate group of rats, the wet weight of the resected remnant pancreas was measured after separating the parabiliary segment from the duodenum. Samples used for measuring wet weight were not examined microscopically. Specimens used for microscopic examination were fixed in $10 \%$ formalin or Carnoy's fixative overnight and embedded in paraffin. Sections with $1.5 \mu \mathrm{m}$ in thickness were cut so that common bile ducts were included in a single plane, and were stained with hematoxylin and eosin. Histology was examined by light microscopy. The number of acinar cells per $\mathrm{mm}^{2}$ area was calculated by counting the number of nuclei of acinar cells on light micrographs taken at $\times 40$ magnification. The proliferation activity was examined by the incorporation of bromodeoxyuridine (BrdU) using a cell proliferation kit (RPN 201, Amersham Pharmacia Biotech Inc., Piscataway, ME, USA). For this purpose, pancreatectomized rats were injected with BrdU intraperitoneally $4 \mathrm{hr}$ prior to removal of remnant pancreas, and the remnant pancreas was processed for light microscopy in the same manner as mentioned above. Sections were stained with anti-BrdU monoclonal antibody as the first antibody after denaturing the intrinsic DNA with $1 \mathrm{~N} \mathrm{HCl}$ for $5 \mathrm{~min}$, followed by treatment with peroxidase-conjugated mouse IgG2a for $1 \mathrm{hr}$. After extensive rinsing with PBS, peroxidase activity was developed 
a)

b)

c)

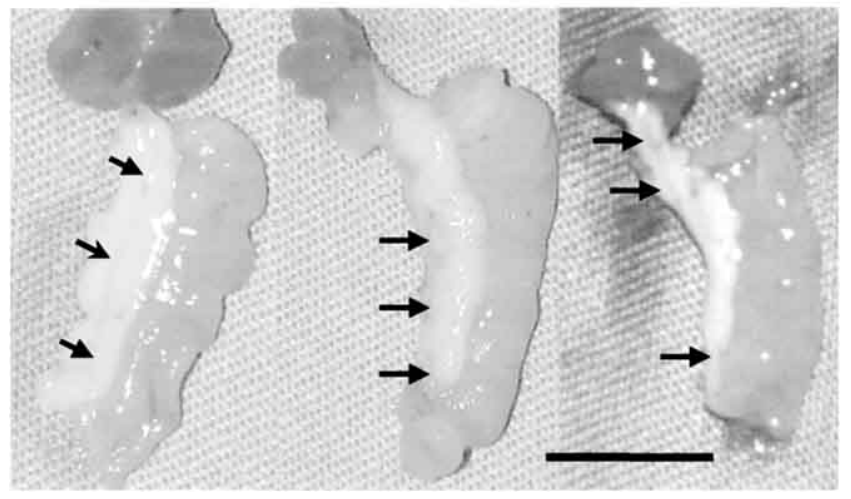

using a mixture of $0.05 \% 3,3^{\prime}$-diamino-benzidine- $4 \mathrm{HCl}$ and $0.01 \% \mathrm{H}_{2} \mathrm{O}_{2}$. Endogenous peroxidase activity was inactivated in advance by treatment with $2 \% \mathrm{H}_{2} \mathrm{O}_{2}$ in methanol for 20 min. The labeling index (LI) was calculated by the ratio of BrdU-positive nuclei in more than 10,000 acinar cells. Calculations were conducted by dividing the remnant pancreas
Fig. 2. Macroscopic findings after pancreatectomy. a) Non-pancreatectomized control rat $(\mathrm{Px}(-)$ group). Note that the remnant pancreas is thin, and that the common bile duct is visible through the tissue. b) 5 days after $90 \%$ pancreatectomy alone (Px group). The remnant pancreas appears thickened and the common bile duct is not detectable through the tissue. c) 5 days after $90 \%$ pancreatectomy and CCK-RA administration (Px+CCK-RA group). Pancreatic remnant is not as thick as that of pancreatectomy alone. The common bile duct is partially recognizable. Arrows indicates common bile duct. $\mathrm{Bar}=1 \mathrm{~cm}$. into three regions: the portion nearest to the duodenum (duodenal region), the middle portion (medial region) and the portion from the common bile duct to the resected margin (stump region). The labeling index (\%) was compared among the three different regions of the remnant pancreas.
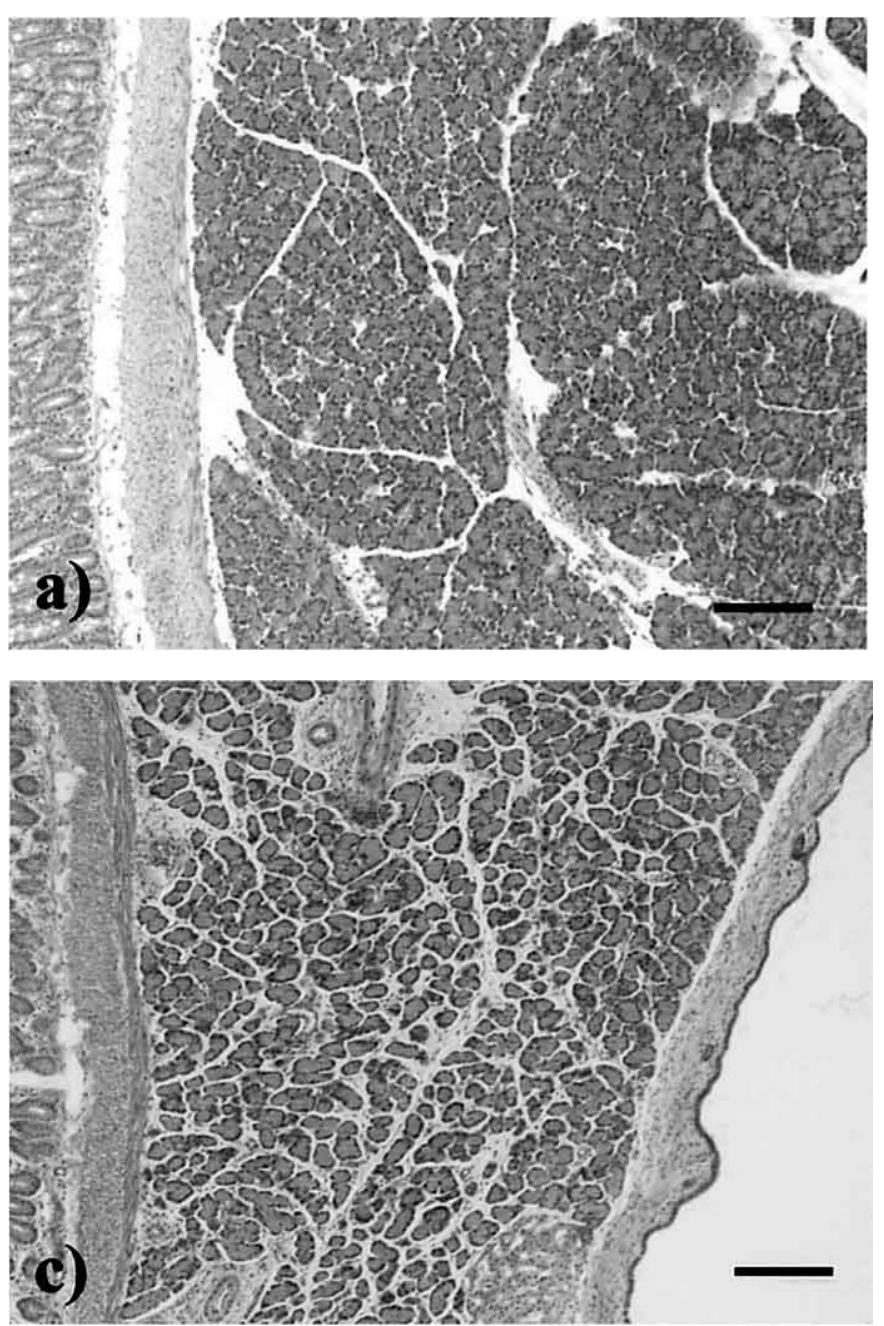

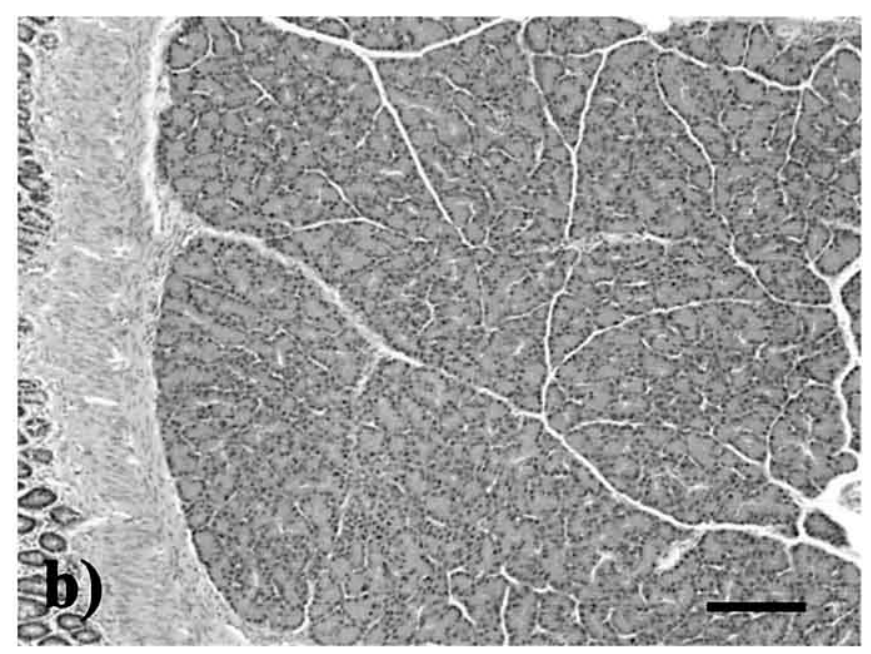

Fig. 3. Histological findings of HE-stained sections. a) In $\mathrm{Px}(-)$ group, the acinar cells are distributed densely with little interstitial tissue. b) In Px group, the acinar cells are distributed even more densely than that of $\operatorname{Px}(-)$ group, with even less interstitial tissue. c) In Px+CCK-RA group, the acinar cells are sparse and interstitial tissue is remarkable. $\mathrm{Bar}=50 \mu \mathrm{m}$. 


\section{Measurement of plasma CCK concentration}

At the time of tissue sampling, blood was also collected from the inferior vena cava and plasma was separated by centrifugation. Plasma CCK was measured by a radioimmunoassay using OAL-656 antiserum and CCK-8 as standard [18]. ${ }^{125}$ I-labeled CCK-39 was used as a tracer. A mixture of standard or sample, assay buffer or free plasma, ${ }^{125} \mathrm{I}-\mathrm{CCK}-39$ and anti-CCK serum OAL-656 was incubated at $4^{\circ} \mathrm{C}$ for $48 \mathrm{hr}$. Then normal rabbit serum and goat antirabbit $\gamma$-globulin were added and incubated at $4^{\circ} \mathrm{C}$ for $48 \mathrm{hr}$.
After centrifugation at $3000 \mathrm{rpm}$ for $30 \mathrm{~min}$, the radioactivity in both the supernatant and the precipitate was counted in a scintillation counter. The sensitivity of this assay was $1.5 \mathrm{pg} /$ tube, equivalent to $7.5 \mathrm{pg} / \mathrm{ml} \mathrm{CCK}-8$. Mean values of 6 rats in each group were compared.

\section{Results}

\section{Macroscopic findings}

In non-pancreatectomized control rats (Px(-) group),

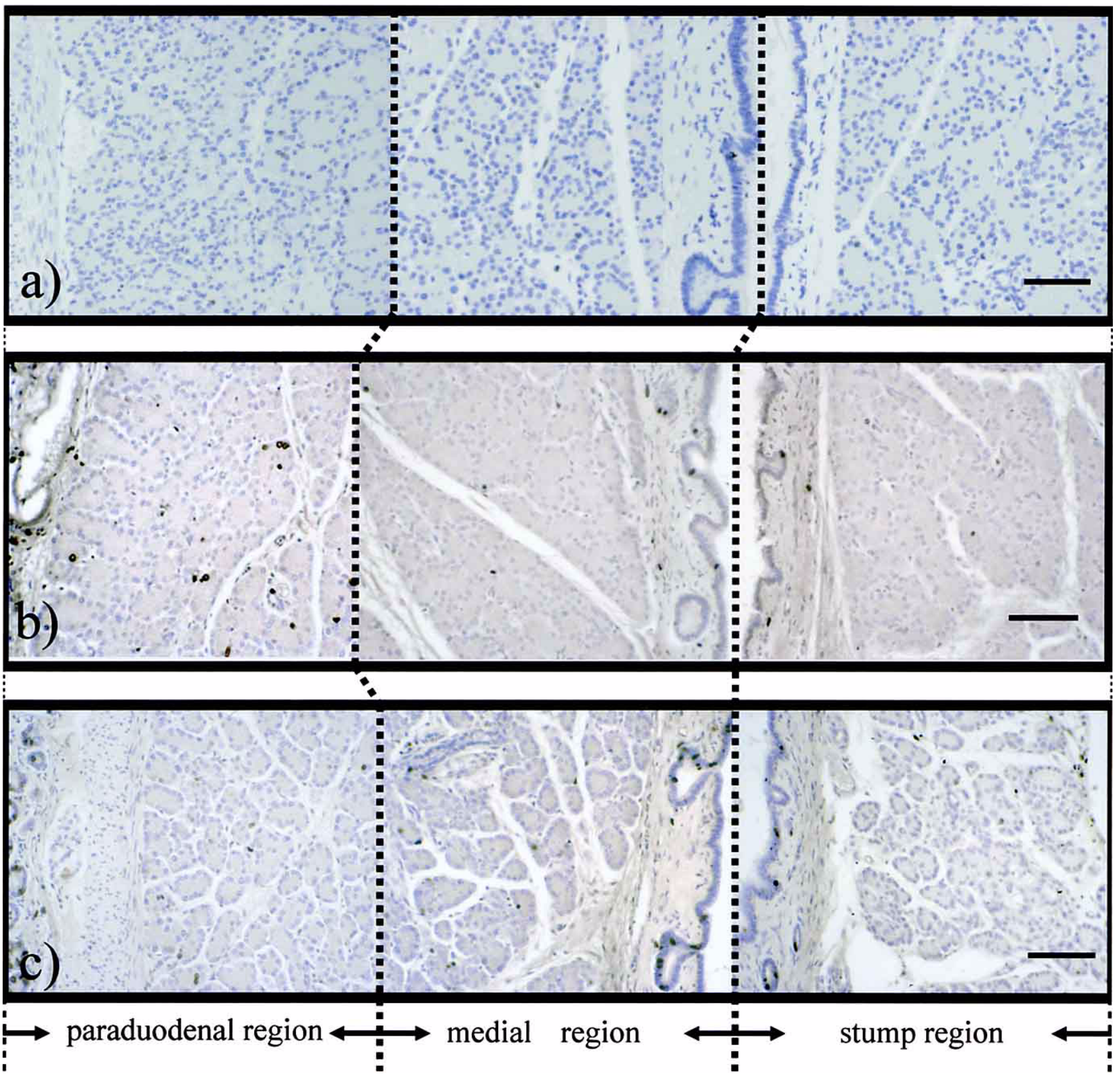

Fig. 4. Uptake of BrdU. a) In $\operatorname{Px}(-)$ group, BrdU-positive acinar cells are sparse in each region and there is no regional difference in proliferation activity among the three regions. b) In Px group, BrdU-positive acinar cells are found more frequently in the paraduodenal region than in the medial and stump regions. c) In Px+CCK-RA group, BrdU-positive acinar cells are less frequently found even in the paraduodenal region. $\operatorname{Bar}=25 \mu \mathrm{m}$. 
the parabiliary segment was so thin that the common bile duct was visible through the pancreatic parenchyma (Fig. $2 \mathrm{a})$. In rats that received pancreatectomy alone (Px group), the remnant pancreas on day 5 after pancreatectomy was thickened in an antero-posterior direction to surround the duodenum, compared to that of the $\operatorname{Px}(-)$ group (Fig. 2b). In contrast, in pancreatectomized rats administered CCK-RA (Px+CCK-RA group), the remnant pancreas was less thickened compared to the Px group. The common bile duct was only partially depictable (Fig. 2c). The weight of the parabiliary segment in the $\mathrm{Px}(-)$ group was $80-90 \mathrm{mg}$. After pancreatectomy, the weight of the parabiliary segment increased to $200-220 \mathrm{mg}$, which was 2.5 times larger than the $\operatorname{Px}(-)$ group. In contrast, the weight of the parabiliary segment in the Px+CCK-RA group was only $100 \mathrm{mg}$, which was half that of the Px group.

\section{Proliferation activity of the acinar cells and endocrine cells}

In $\operatorname{Px}(-)$ group, the acini were distributed densely with relatively small amounts of interstitial tissue. In the Px group, the acini became more densely distributed and only sparse interstitial tissue could be recognized. In the Px+CCK-RA group, the area occupied by interstitial connective tissue increased, whereas the parenchymal tissue became atrophic. As a result, the common bile duct epithelium was prominently visible (Fig. 3). In Px(-) group, the LI in acinar cells was approximately $1 \%$ (Fig. 4a), and regional difference was not remarkable (Fig. 5). A mature islet consisted of 100-200 endocrine cells in a sectional plane, and only about 1-2 cells showed positive BrdU labeling (Fig. 6), indicating LI to be roughly $0.5-1 \%$ in $\mathrm{Px}(-)$ group (Fig. 7). In the Px group, BrdU-positive cells were found frequently in the paraduodenal region; 7-8 BrdU-positive cells were

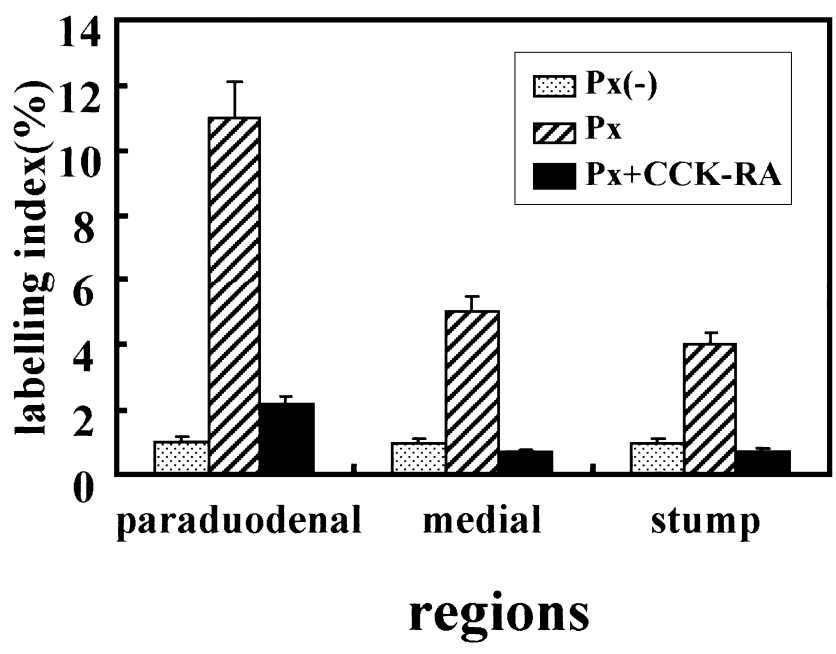

Fig. 5. Labeling indices of acinar cells in each region, and effect of CCK-RA. In Px group, acinar cells take up more BrdU in the paraduodenal region than in the medial and stump regions. BrdU labeling indices decrease with increasing distance from the duodenum. In Px+CCK-RA group, labeling index decreases to $1 / 6-1 / 3$ in each region. recognized in a $\times 200$ magnified field (Fig. 4b), indicating LI to be roughly $10 \%$, which was 10 times higher than that in the $\mathrm{Px}(-)$ group. In the medial and stump regions, LI were $5 \%$ and $4 \%$, respectively. LI decreased gradually as the area examined became closer to stump region (Fig. 5). In mature islets of the Px group, about 10 endocrine cells showed positive reaction for BrdU among a total of 100-200 cells (Fig. 6), and LI was calculated to be approximately 5\% (Fig. $7)$. In the Px+CCK-RA group, BrdU-positive cells were less abundant even in paraduodenal region (Fig. 4c). LI was calculated to be approximately $2 \%$ in paraduodenal region, and $0.7 \%$ in medial and stump regions. An $80 \%$ decrease of proliferation activity was seen almost equally in the three regions (Fig. 5). In endocrine cells of the $\mathrm{Px}+\mathrm{CCK}-\mathrm{RA}$ group, a small number of BrdU-positive cells were found (Fig. 6) and LI was calculated to be approximately $1.2 \%$. A $70 \%$ decrease of proliferation activity was seen as compared to the Px group (Fig. 7).

\section{Plasma CCK concentration}

Plasma CCK concentrations are summarized in Fig. 8. Pancreatectomy was found to induce an increase in plasma CCK concentration. Administration of CCK-RA caused a $10 \%$ decrease in plasma CCK concentration compared to the Px group, but plasma CCK concentration was still higher than that in the $\operatorname{Px}(-)$ group.

\section{Discussion}

\section{Role of CCK in the regeneration of remnant pancreas}

The pancreatic tissue of non-pancreatectomized rats has a very low mitotic activity, but not zero activity. This background mitotic activity is considered to maintain tissue volume by turnover of the constituent cells [21]. The remnant pancreas on day 5 after pancreatectomy thickened and the distribution of acini become dense with less amount of interstitial tissue. Qualitative and quantitative study for BrdU uptake indicated that proliferation activity increased gradually after pancreatectomy and reached a peak on day 5 . Plasma CCK concentration was twice as much as that of non-pancreatectomized rats, indicating that partial pancreatectomy stimulated secretion of endogenous CCK. Under this condition of augmented CCK level, increases in wet weight, acinar cell density and proliferation activity were observed simultaneously in the remnant pancreas. Increased proliferation activity of islet cells suggested that CCK induced proliferation not only in exocrine but also in endocrine tissue.

Administration of CCK-RA to pancreatectomized rats resulted in a $10 \%$ decrease in plasma CCK concentration and various morphological changes compared with Px group. Enlargement of remnant tissue was unremarkable macroscopically, and acini were separated from each other by a large amount of connective tissue. Wet weight of the remnant pancreas decreased compared with Px group, and distribution of acinar cells became sparse, showing a histological appearance similar to that of $\mathrm{Px}(-)$ group. These 

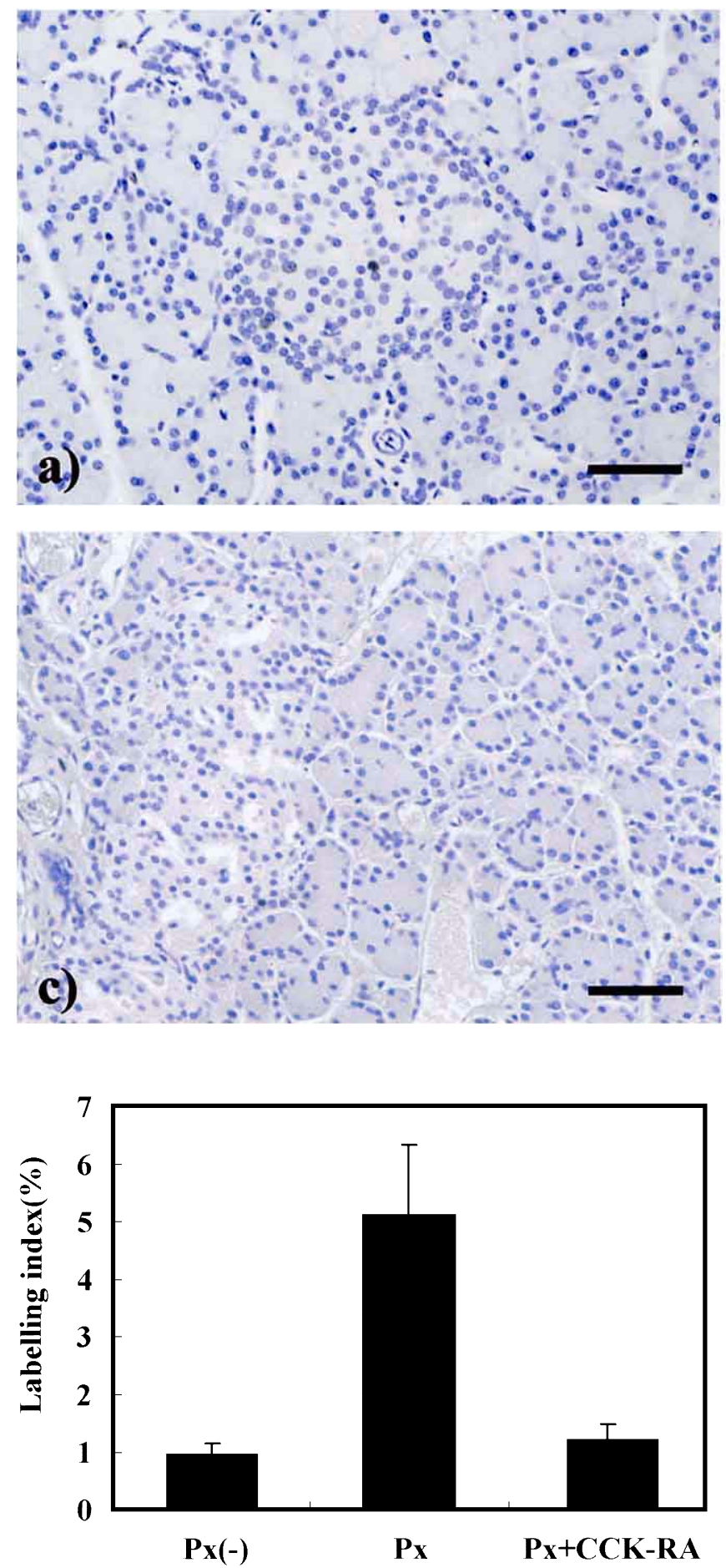

Fig. 7. Labeling indices of islet cells. The number of BrdU-positive cells is reduced by almost one half in Px+CCK-RA group compared to Px group.

findings indicated proliferation of acinar cells was inhibited totally by the effects of by CCK-RA. Uptake of BrdU was very low in the islet cells and the amount was not different from that of $\mathrm{Px}(-)$ group. From the evidence, it was concluded that $90 \%$ pancreatectomy induced proliferation of both exocrine and endocrine cells through elevated CCK.

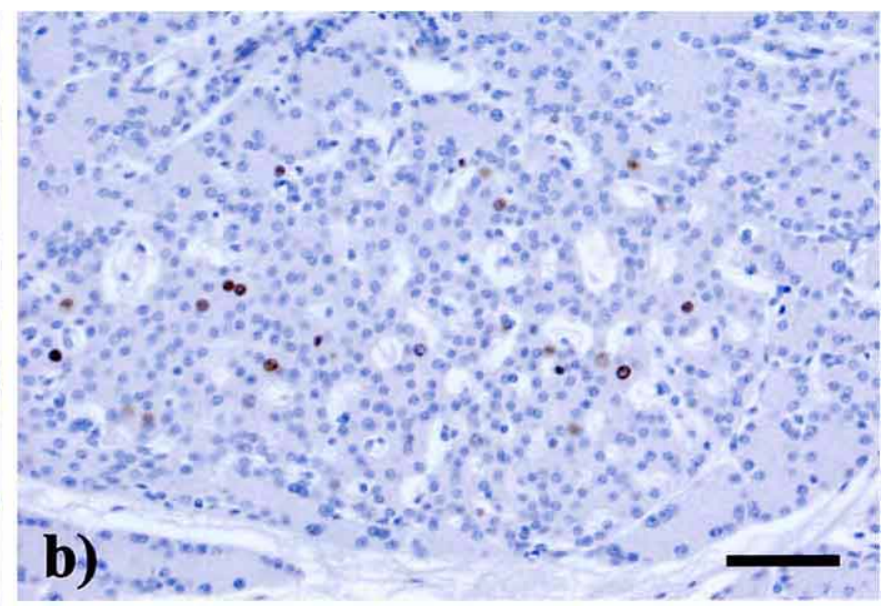

Fig. 6. BrdU incorporation in islet cells. a) In islet of $\mathrm{Px}(-)$ group, BrdU-positive cells are few in number. b) In islets of Px group, BrdU-positive cells increase in number. c) In islets of $\mathrm{Px}+\mathrm{CCK}-\mathrm{RA}$ group, a few positive cells are observed. $\mathrm{Bar}=25$ $\mu \mathrm{m}$.

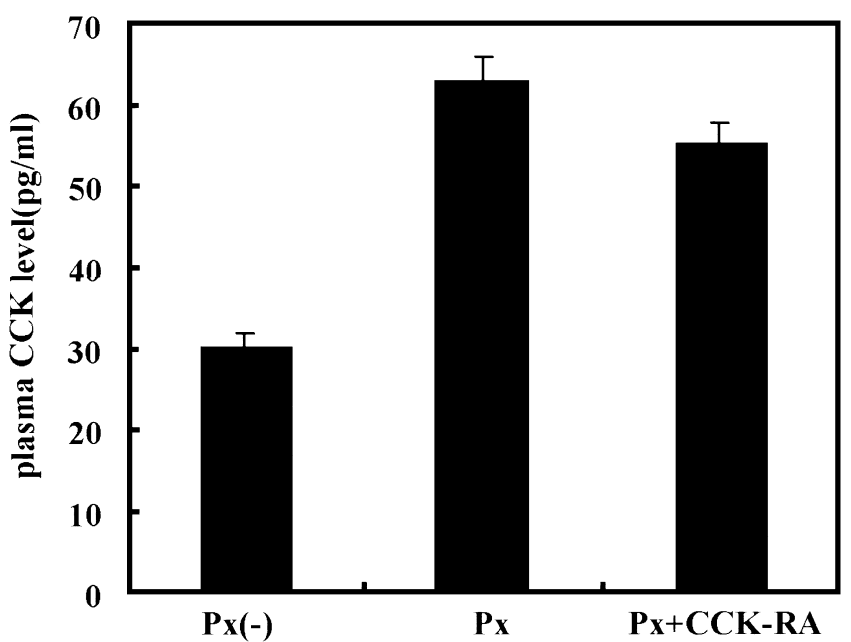

Fig. 8. Plasma CCK concentrations.

Miyasaka et al. [18] performed 30\% pancreatectomy in OLETF (Otsuka Long Evans Tokushima Fatty) rats that showed no CCK-A receptor gene expression because of a genetic abnormality, and reported that the wet weight, DNA concentration and protein concentration were reduced in the remnant pancreas of pancreatectomized OLETF rats com- 
pared with LETO (Long Evans Tokushima Otsuka) rats. They concluded that deficiency of CCK-A receptor retards normal pancreatic growth with age, and that CCK-A receptor is not an absolute requirement for pancreatic normal growth but is important for regeneration after pancreatic damage.

Although the trophic effect of CCK on acinar cells has been well documented, its effect on islet cells has yet to be reported. Imoto et al. [12] and Mineo et al. [17] reported that normal growth of both acinar and islet cells were inhibited in rats and sheep by administration of CCK-RA. Expression of mRNA coding CCK-A receptor was also reported not only in acinar cells but also in beta cells [2]. Our study demonstrated that plasma CCK concentration was reduced by only $10 \%$ after CCK-RA administration. Although the amount was not reduced to the level of $\operatorname{Px}(-)$ group, atrophy of the remnant pancreas was recognized nonetheless. It is very likely that decreased pancreatic function brought about enhancement of CCK secretion that stimulated proliferation of exocrine as well as endocrine cells; however, the sequential reaction might not take place when CCK-receptor was blocked by the antagonist. In contrast, Miyasaka et al. [18] reported no apparent difference in plasma CCK concentration between normal and deficient rats of the CCK-A receptor gene. The discrepancy might be attributable to the difference in degree of pancreas resection.

\section{Effect of endogenous CCK on regional differences in regeneration}

We have already reported high proliferation activity in the acinar cells after $90 \%$ pancreatectomy [9]. Regional difference in mitotic activity of acinar cells was evident in the remnant pancreas; that is, acinar cells proliferated more actively in the paraduodenal region than in the medial and stump regions [9]. In the present study, we paid special attention to CCK produced by duodenal chromaffin cells, as a candidate to cause regional differentiation. If endogenous CCK affected the remnant pancreas by a paracrine mechanism, identical LIs would be expected in the three regions after treatment with CCK-RA. However almost $80 \%$ decrease of proliferation activity was found uniformly in the three regions. Thus, it seems unlikely that endogenous CCK affects acinar cells directly by a paracrine mechanism via chromaffin cells in the adjacent duodenum. Alternately, anatomical distribution of capillary vessels or postsynaptic neurons could be expected to contribute to regional differences. However, scanning electron microscopic findings showed that the capillary network in rat pancreas appeared to be homogenous, with no discernible local differences [19]. Therefore, it seems unlikely that regional difference of proliferation activity arises from differences in capillary network distribution. Sakagami et al. [26] reported that increased secretion of endogenous CCK after oral administration of camostat (Foipan ${ }^{\circledR}$, a kind of proteinase inhibitor), induced pancreatic blood flow, and that the effect was inhibited by CCK-RA. They suggested that there might be a vascular dilatation mechanism mediated by the CCK-A receptor in the pancreas. After reduction of normal pancreatic tissue (especially the volume of acinar cells), such as by pancreatitis or pancreatectomy, the endogenous CCK might increase the blood flow in pancreatic tissue not by anatomical changes of the vascular system but by dilatation of the vessels; however, it is not clear whether there are regional differences of distribution in the dilatation of the vessels. Thus, regional differences in proliferation activity of acinar cells could be explained by assuming the existence of regional differences in pancreatic vessels. In contrast, amylase secretion was stimulated by endogenous CCK via neurosecretion in human pancreas; that is, exogenous stimulation by carbacol, but not CCK, induced amylase secretion from isolated acinar cells in vitro [7]. This fact may suggest that regional differences of proliferation activity may occur in the presence of topographical differences of innervation. We presumed that endogenous CCK affected the CCK-A receptor through blood flow in the pancreatectomized rat, and that regional differences in regeneration activity could be attributed to differences in vascular distribution as well as autonomic nervous system. Distributional differences of CCK-A receptor may affect the regional differences in the regeneration of exocrine portion, but the presence of such differences needs to be determined by future studies.

In conclusion, endogenous CCK is one of the essential factors for pancreatic regeneration. We speculate that regional differences in proliferation activity of the remnant pancreas might arise from differences in distribution of vascular flow and/or autonomic neurons, but further studies are required to clarify this point. Secretion of endogenous CCK is promoted by partial pancreatectomy, which results in elevated blood CCK level and trophic effects on acinar cells and islet cells. These effects are inhibited by CCK-RA. The molecular mechanism by which CCK secretion is promoted remains to be elucidated.

\section{Acknowledgments}

SR27897B was kindly provided by Dr. Kimitoshi Takemura, Nippon Sanofi Co., Ltd. The authors express their sincere gratitude to Prof. M. Majima for providing information about SR27897B, and Y. Masaki, T. Fujiu, A. Nakagawa and O. Katsumata for technical assistance. The authors are also grateful to the staff of Department of Anatomy, Kitasato University School of Medicine for valuable discussion. This research was supported by Grants-inAid for Scientific Research (B, 11470008) and for Young Scientists (B, 13770667); High-tech research center grant from the Ministry of Education, Culture, Sports, Science and Technology; and Grant-in-Aid for Scientific Research (B, 13557003 and C, 15591358) from Japan Society for the Promotion of Science. This research was conducted under financial support from the Integrative Research Program of the Kitasato University Graduate School of Medical Science (1998-1999, 2000-2001, 2002-2003), the Parents' Association of Kitasato University School of Medicine, and the 
Pancreatic Research Foundation of Japan (1999).

\section{References}

1. Barrowman, J. A. and Mayston, P. D. (1974) The trophic influence of cholecystokinin on the rat pancreas. J. Physiol. 238; 73 75 .

2. Bourassa, J., Laine, J., Kruse, M. L., Gagnon, M. C., Calvo, E. and Morisset, J. (1999) Ontogeny and species differences in the pancreatic expression and localization of the $\mathrm{CCK}(\mathrm{A})$ receptors. Biochem. Biophys. Res. Commun. 260; 820-828.

3. Brants, E. and Morisset, J. (1976) Trophic effect of cholecystokinin-pancreozymin on pancreatic acinar cells from rats of different ages. Proc. Soc. Exp. Biol. Med. 153; 523-527.

4. de Tullio, P., Delarge, J. and Pirotte, B. (1999) Recent advances in the chemistry of cholecystokinin receptor ligands (agonists and antagonists). Curr. Med. Chem. 6; 433-455.

5. DiMattei, E. (1885) Degri effeti della irritazione sugli elementi glandulari del pancreas. Giornale Reale Accad. Med. Torino Ser. $33 ; 476$.

6. Fitzgerald, P. J., Carol, B. M. and Rosenstock, L. (1966) Pancreatic acinar cell regeneration. Nature 212; 594-596.

7. Funakoshi, A., Shinozaki, H. and Miyasaka, K. (2000) Pancreatic exocrine function and CCK receptors. J. Biliary Tract Pancreas $21 ; 205-212$.

8. Gully, D., Frehel, D., Marcy, C., Spinazze, A., Lespy, L., Neliat, G., Maffrand, J-P. and Le Fur, G. (1993) Peripheral biological activity of SR27897: a new potent non-peptide antagonist of CCK-A receptors. Eur. J. Pharmacol. 232; 13-19.

9. Hayashi, K., Takahashi, T., Kakita, A. and Yamashina, S. (1999) Regional differences in the cellular proliferation activity of the regenerating rat pancreas after partial pancreatectomy. Arch. Histol. Cytol. 62; 337-346.

10. Hayashi, K. Y., Tamaki, H., Handa, K., Takahashi, T., Kakita, A. and Yamashina, S. (2003) Differentiation and proliferation of endocrine cells in the regeneration rat pancreas after $90 \%$ pancreatectomy. Arch. Histol. Cytol. 66; 163-174.

11. Herrington, M. K. and Adrian, T. E. (1995) On the role of cholecystokinin in pancreatic cancer. Int. J. Pancreatol. 17; 121-138.

12. Imoto, I., Yamamoto, M., Jia, D. M. and Otsuki, M. (1997) Effect of chronic oral administration of the CCK receptor antagonist loxiglumide on exocrine and endocrine pancreas in normal rats. Int. J. Pancreatol. 22; 177-185.

13. Johnson, L. R. (1977) New aspects of the trophic action of gastrointestinal hormones. Gastroenterology 72; 788-792.

14. Kreiss, C., Schwizer, W., Borovicka, J., Jansen, J. B., Bouloux, C., Pignol, R., Bischof-Delaloye, A. and Fried, M. (1995) Effect of lintitript, a new CCK-A receptor antagonist on gastric emptying of a solid-liquid meal in humans. Gastroenterology 108; A632.

15. Landi, M., Croci, T., Gully, D., Le Fur, G., Maffrand, J. P. and Manara, L. (1996) The CCK-A antagonist SR27897B partially restores rat gastric emptying delayed by intraduodenally fed fats Gastroenterology 110; A701.

16. Mantey, S. A., Pisegna, J. R., Wank, S. A. and Jensen, R. T.
(1994) Comparative ability of agonists and antagonists to discriminate human CCK-A and CCK-B receptors. Gastroenterology 106; A305.

17. Mineo, H., Iwaki, N., Kogishi, K., Onaga, T., Kato, S. and Zabielski, R. (1997) Effects of proglumide on cholecystokinin8 -induced exocrine and endocrine pancreatic responses in conscious sheep. Comp. Biochem. Physiol. A Physiol. 118; 759-764.

18. Miyasaka, K., Ohta, M., Masuda, M. and Funakoshi, A. (1997) Retardation of pancreatic regeneration after partial pancreatectomy in a strain of rats without CCK-A receptor gene expression. Pancreas 14; 391-399.

19. Murakami, T., Miyake, T., Tsubouchi, M., Tsubouchi, Y., Ohtsuka, A. and Fujita, T. (1997) Blood flow patterns in the rat pancreas: a simulative demonstration by injection replication and scanning electron microscopy. Microsc. Res. Tech. 37; 497508 .

20. Nagy, I., Hajnal, F., Mohacsi, G., Nemeth, J., Laszik, Z. and Pap, A. (1993) Pancreatic trophism in experimental liver cirrhosis. Int. J. Pancreatol. 14; 157-166.

21. Ohlsson, B., Axelson, J., Sternby, B., Rehfeld, J. F. and Ihse, I. (1995) Time-course of pancreatic changes following long-term stimulation or inhibition of the CCK-A receptor. Int. J. Pancreatol. 18; 59-66.

22. Pearson, K. W., Scott, D. and Torrance, B. (1977) Effects of partial surgical pancreatectomy in rats. I. Pancreatic regeneration. Gastroenterology 72; 469-473.

23. Petersen, H., Solomon, T. and Grossman, M. I. (1978) Effect of chronic pentagastrin, cholecystokinin, and secretin on pancreas of rats. Am. J. Physiol. 234; E286-E293.

24. Rodriguez, A. I., Manso, M. A., Garcia-Montero, A. C., Orfao, A. and Dios, I. (1977) Long-term blockade of cholecystokinin (CCK): Effects of L364,718 (a CCK receptor antagonist) on pancreatic enzyme storage and secretion. Pancreas 15; 314-322.

25. Saillan-Barreau, C., Dufresne, M., Clerc, P., Sanchez, D., Corominola, H., Moriscot, C., Guy-Crotte, O., Escrieut, C., Vaysse, N., Gomis, R., Tarasova, N. and Fourmy, D. (1999) Evidence for a functional role of the cholecystokinin-B/gastrin receptor in the human fetal and adult pancreas. Diabetes 48; 2015-2021.

26. Sakagami, J., Ohta, A., Kataoka, K. and Kashima, K. (1996) Role of cholecystokinin on pancreatic pathophysiology. Gastroenterology 23; 76-83.

27. Sakamoto, C., Goldfine, I. D., Roach, E. and Williams, J. A. (1985) Localization of saturable CCK binding sites in rat pancreatic islets by light and electron microscope autoradiography. Diabetes 34; 390-394.

28. Scow, R. O. (1957) Total pancreatectomy in the rat: operation, effects, and postoperative care. Endocrinology 60; 359-367.

29. Watanapa, P., Egan, M., Deprez, P. H., Calam, J., Sarraf, C. E., Alison, M. R. and Williamson, R. C. (1992) Role of cholecystokinin in pancreatic adaptation to massive enterectomy. Gut 33; 959-964.

30. Williams, J. A., Sankaran, H., Roach, E. and Goldfine, I. D. (1982) Quantitative electron microscope autoradiographs of 125I-cholecystokinin in pancreatic acini. Am. J. Physiol. 243; G291-G296. 